\title{
Infinitive Patterns in English in the Register of Information and Communication Technologies
}

\author{
Dr. Sladjana Živković \\ College of Applied Technical Sciences, Serbia
}

\begin{abstract}
This paper offers a detailed study of infinitive patterns present in the register of information and communication technologies (ICT) in the English language, the focus of investigation being their syntax. This study relies on the current theoretical background in syntax, and was performed on the latest articles in this field as found in the most renowned journals in the ICT area of expertise. The reason for commencing this investigation was the authors' finding that in ICT register infinitive constructions are highly present as they are an 'economical' way of communication, as 'economical' is one of the primary characteristics and demands in all ICT communications. The authors have made a contribution in this field by precisely defining which constructions appear in this particular register, and by enumerating them. Therefore, a detailed study of the occurrence of infinitive construction has revealed that there appear two bare infinitive patterns and fifteen patterns with to-infinitive in the mentioned register.
\end{abstract}

Keywords: $t o$-infinitive, bare infinitive, English, ICT register

\section{Introduction}

The English language is characterized by three different types of sentential complements: finite clauses, infinitive clauses and clauses with -ing form (Fanego 2004: 8). This paper presents an investigation of the non-finite type, namely, the infinitive. In relation to their importance, changes in the function and use of the various types of non-finite complement clauses remain an under-explored area of research (Mair 2006: 140). The reason for our investigation relies precisely on this fact. As practitioners of ESP, English for Science and Technology in particular, we are highly aware that infinitives are neither described nor investigated closely enough, and that in our area of expertise they are highly present for a very important reason. Their use is directly linked to the basic premises of the language that is characteristic for the today's fastest developing science, Information and Communication Technologies. The use of infinitives, as we found, fulfils the need for economical, condense communication as it often offers a reduced number of words within a clause.

Hereby, it is important to quickly review the development of the present infinitive forms and show why it is relevant to investigate them from the viewpoint of syntax. Comparative grammar has shown that the to-infinitive in Old English was an inflected verbal substantive, and now, it has become identical in form with the base of the verb. Gradually, the infinitive adopted more and more of the syntactic peculiarities of verbs, and lost those of substantives. The infinitive is now a purely verbal form. Although it has retained its substantival character as it can stand as a subject or object (Jespersen 2006: 269). The meaning of to has changed (having lost its prepositional character), and has grammaticalized into an infinitive marker (Fanego 2004: 10). 


\section{Infinitive patterns}

It is a well-known fact that English has two basic infinitive verb forms: the to-infinitive which is the base form preceded by to, and bare infinitive, which is the base form of the verb (Alexander 1993: 278, Duffley 2002: 28). In comparing the to-infinitive with the bare infinitive Duffley (1992: 15) says that to should bring some meaning of its own to the construction. Here, we will not investigate the differences between bare and marked infinitival complements, we will just analyze the infinitival constructions with both of them.

Rosenbaum (1967 in Duffley: 41) classifies the to-infinitive with the verbs begin, cease, continue, fail, manage, refuse and start as instances of intransitive verb phrase complementation, and with the verbs like, desire, intend and want as object noun phrase complementation.

The form of the bare stem is the same as the simple form of the verb which occurs in subjunctive (Duffley 2002: 28). The bare infinitive has been restricted, so that now it is used chiefly after auxiliary verbs, and in a few other cases in which the connection between the infinitive and what precedes it is very close (Jespersen 2006: 269). The pattern verb + bare infinitive is rare in all registers (Biber et al. 1999), as is also evident in the ICT register.

Based on our research findings, we have identified the following infinitive patterns in English in ICT register:

\subsection{The bare infinitive pattern}

I

Here we will start with the infinitive without to after modal verbs (will, shall, would, should, can, could, may, might, must)

modal + infinitive (without to)

This pattern is exemplified by the examples:

1. Drivers must help users and prevent them from inappropriately accessing a computer's devices and files.

2. The 2-bit pointer can permit the expansion of data memory.

The examples show that the modal verbs, in our cases, must, can, appear before the verbs (help, permit).

In both examples the modal verbs modify the process which is expressed by the infinitive of the verbs.

\section{II}

The second pattern is the infinitive without to in passive after modal verbs

modal + infinitive (without to) in passive

These examples will serve to illustrate this:

1. It is a small application that can be installed and executed within a web page by an end user.

2. The file will be downloaded to current local directory.

It is clear that the pattern for the mentioned examples looks like this:

modal verb + infinitive (without $t o$ ) + past participle

1. can + be + installed

2. will + be + downloaded 


\subsection{The to-infinitive pattern}

I

Here, we present the to-infinitive after modal verbs to make passive

Examples of this kind are considered below:

1. Most computer software needs to be installed before they can be used.

2. The SLAC needs to be considered a third-generation integrated circuit.

We may observe, in both examples, that after modal verbs (need) passive infinitives are used. The pattern is:

modal verb + to-infinitive + past participle

need + to be + installed

need + to be + considered

II

Some nouns, like opportunity, are followed by a to-infinitive or a preposition (Alexander 1993: 278). 1. opportunity + to-infinitive

The following examples show a clear distinction:

1. a) There is an opportunity to open downloaded files.

b) There is an opportunity for opening downloaded files. (In this case the preposition for is used).

As we can see from the examples above, the noun opportunity is followed by a verb in two ways:

In the first example it is: opportunity + to-infinitive

$$
\text { opportunity + to open }
$$

In the second example: opportunity + for (preposition) + gerund

opportunity + for + opening

III

After the noun attempt the to-infinitive is usual. An interesting point is that the verb attempt can be construed with both the infinitive and the -ing form (Duffley 2006: 40).

attempt + to-infinitive

This is illustrated in the following examples:

1. There was an attempt to move the file pointer before the beginning of the file.

2. There has been an attempt to reset the display driver and recover from timeout failed.

Hence, in both cases the pattern is: noun + to-infinitive

1. attempt + to move

2. attempt + to reset

IV

$\underline{\text { To-infinitive after the noun ability }}$

ability + to-infinitive

The following examples are essential for the mentioned construction:

1. Quantum computers share theoretical similarities with non-deterministic and probabilistic computers, like the ability to be in more than one state simultaneously.

2. You have the ability to restrict document download in Google Docs. 
Here, we can observe the following pattern:

noun (ability) + to-infinitive

1. ability + to be

2. ability + to restrict

$\mathbf{V}$

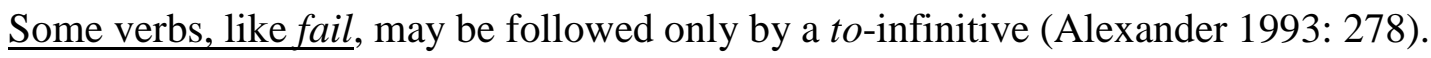

fail + to-infinitive

Let us consider some examples:

1. My desktop failed to detect the local area network.

2. Once the Titanium installer for Windows downloaded, I launched the install but it failed to download the rest of the files necessary for install.

From these examples we can notice the pattern:

verb (fail) + to-infinitive

1. fail + to detect

2. fail + to download

VI

Infinitive after the verb allow

Constructions containing the verb allow are very common in English (Egan 2008: 214). There are many situations in which it may be employed. Allow must be followed by to (Duffley 1992: 83), allow + to-infinitive.

The following examples are of this type:

1. Open source software generally allows anyone to create modifications of the software.

2. Windows 8 will allow developers to build apps in several programming languages.

As we can observe, the verb allow is used with an object (anyone, developers) and an infinitive.

The pattern is: the verb (allow) + object + to-infinitive

$$
\begin{aligned}
& \text { allow }+ \text { anyone }+ \text { to create } \\
& \text { allow }+ \text { developers }+ \text { to build }
\end{aligned}
$$

\section{VII}

Some verbs, like begin, may be followed by a to-infinitive or the -ing form (Alexander 1993: 278). Duffley (2006: 39) states that the to-infinitive construction after begin and start has the function of a goal-circumstantial (1.a), the role of -ing by contrast (1.b), is that of a direct object.

The following examples will serve to explain the mentioned pattern:

1. a) We have begun to explore the use of adapted computer technology. (begin + toinfinitive)

b) We have begun exploring the use of adapted computer technology. (begin + ing)

The two formal patterns are exemplified in 1.a) and 1.b).

The pattern for the first case is: verb (begin) + to-infinitive 
begin + to explore

for the second case it looks like this:

verb (begin) + ing form

begin + exploring

Quirk et al. defines the difference between the to-infinitive and -ing construction as hypothetical meaning (to-infinitive) and actuality (-ing). According to Wierzbicka (1988) toinfinitive is future expactation, -ing is ongoing occurrence. The to-infinitive is defined to contain the notion of movement leading up to a point, the -ing form as having a direct object value (Duffley 2006).

\section{VIII}

Infinitive after the verbs intend, want

The to-infinitive with the verbs intend, want is classified as an object noun phrase complementation (Rosenbaum 1967: 121). It should be pointed out that verbs, such as want, apply to unrealized possibility (Egan 2008: 53).

We have found the following examples:

1. Find the source code to the package you want to compile.

2. Designers intend to create new video games.

Here, in the first sentence, the to-infinitive to compile serves to function as a complement of the verb want. In the second sentence, the to-infinitive to create serves to function as a complement of the verb intend.

The pattern is: verb (want, intend) + to-infinitive

1. want, intend + to compile

2. want, intend + to create

\section{IX}

To does not have any independent meaning, it is merely a sort of a marker of the following infinitive (Chomsky 1957: 100). It is well known in the literature that the preposition to developed into an infinitival marker when it became combined with an infinitive (Fischer 2000: 451). The infinitive marker is the word to which we may use in front of the base form of a verb, thereby changing the bare infinitive into a to-infinitive. To may often be expanded to so as to or in order to (Alexander 1993: 278).

The construction so as to / in order to + infinitive is found in the following examples:

1. You will first uncompress the file /so as to/in order to install the driver.

2. The console attached to the machine /so as to/in order to run the installation program in graphical mode.

$\mathbf{X}$

It is worth noting that the to-infinitive functioning as a subject is usually found in anticipatory it-extraposition construction (Quirk et al. 1985: 723). They describe extraposition as postponement which involves the replacement of a postponed element by a substitute form, anticipatory it.

We offer two cases in which extraposition is possible: 
1. It appears to recognize the file type.

2. It seems to download a file.

Here, extraposition appears with verbs such as appear and seem.

The pattern for the foirst example is:

for the second example:

preposition (it) $+($ appear $)+$ to-infinitive

$$
\text { it }+ \text { (appear) }+ \text { to recognize }
$$

$$
\begin{array}{r}
\text { preposition }(\text { it })+(\text { seem })+\text { to-infinitive } \\
\text { it }+(\text { seem })+\text { to download }
\end{array}
$$

\section{XI}

This specific construction can also be found in a sentence with it would be better as in 1.a), and it is important in 1.b).

Consider the following examples:

1. a) It would be better to install the program and use the external hard drive for backup of the files for Quickbooks.

1. b) It is important to protect your computer against new viruses.

With regard to these cases, the patterns look like this:

For the first case: it would be better + to-infinitive

it would be better + to install

for the second case: it is important + to-infinitive

it is important + to protect

\section{XII}

In addition to separability from the verb, there appears a change which includes separability of for and to.

It has to be mentioned that the for-to infinitive construction frequently appears in ICT register.

After certain adjectives (Jespersen 2006: 280) that express importance (important), the pattern (important) for + object + infinitive is often used in ICT register.

1. It is important for a programmer to pay attention to important aspects involved in web designing.

1. It is better for you to protect your computer from malware by installing antivirus software.

The construction (important) for + object + infinitive is shown in our examples:

(important) for + a programmer + to pay

(better) for + you + to protect

\section{XIII}

Fischer (1999:17) talks about new developments as contributing to the semantic independence of to before the infinitive. This is the appearance of split infinitives. The split infinitives show that grammaticalization was interrupted (Fischer 1999).

In contemporary English, splitting involves an adverb between the verb and its marker. 
Splitting infinitives is a natural tendency for native speakers in English because it corresponds to the very structure of the English language (Duffley 2002: 23). Split infinitives show their verbal quality in that they allow verbal qualifiers such as adverbs to appear before the verb (Fisiak 1994: 275).

The interpretation of split infinitive is given in the examples below:

1. It takes a certain amount of memory to (effectively) load and run certain programs.

2. It is possible to (quickly) reset many of the shooting settings to their default values by simply holding two buttons simultaneously for two seconds.

Here, the situation is the following: the adverbs effectively, quickly appear between the verbs load, reset and the marker to.

\section{Conclusion}

In their work, both authors have noticed a high occurrence of infinitive constructions. They believe that the reason for this is the fact that these types of constructions significantly allow the reduction of the number of words needed to convey information. At the same time, they offer precision in expression. These are the basic and most required characteristics inherent in the communication for one of today's fastest developing science, information and communication technologies. This finding was the starting point for commencing a more detailed research into the types of infinitive constructions as found in this register.

The results of our research are as follows: as infinitive constructions are broadly divided into the bare infinitive pattern and the to infinitive pattern, we have found that the first class is present in two types, and the latter in fifteen. Each case is documented with an example from general ICT register that well enough illustrates the use of it. We believe that by enumerating and detailing these infinitive structures we have proved the rationale for their frequent occurrence in the ICT register.

\section{References}

Alexander, L.G. 1993. Longman Advanced Grammar: Reference and Practice. Longman Group UK Limited, UK.

Biber, Douglas, et al. 1999. Longman Grammar of Spoken and Written English. Harlow: Pearson Education Limited.

Chomsky, Noam. 1957. Syntactic Structures. The Hague: Mouton \& Co.

Collins Cobuild English Grammar. 1990. William Collins Sons \& Co Ltd, London and Glasgow. The University of Birmingham.

Duffley, Patrick. J. 1992. The English Infinitive. London / New York. Longman.

Duffley, J. Patrick. 2006. The English Gerund-Participle - A Comparison with the Infinitive. Peter Lang Publishing, Inc., New York.

Egan, Thomas. 2008. Non-finite complementation: A usage-based study of infinitive and -ing clauses in English. Rodopi. B.V. The Netherlands. 


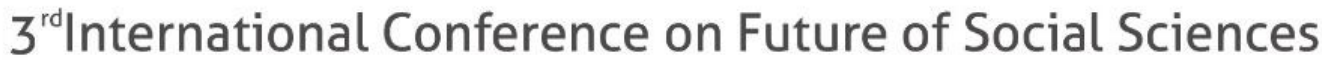

\section{5 - 7 March 2021}

Fanego, Teresa. 2004. Some strategies for coding sentential subjects in English: From exaptation to grammaticalization. Studies in Language 28(2): 321-361.

Fischer, Olga. 1997. The grammaticalization of infinitival to in English compared with German and Dutch. In Language History and Linguistic Modelling. Vol.1: Language History, Raymond Hickey \& Stanislaw Puppel (eds.), 265-280. Berlin. Mouton de Gruyter.

Fischer, Olga. 2000. Grammaticalization: Unidirectional, non-reversable? In Pathways of change. Grammaticalization in English \{Studies in Language Companion Series 53\}, Olga Fischer, Anette Rosenbach \& Dieter Stein (eds.), 149-169. Amsterdam. John Benjamins.

Fisiak. Jacek 1994. Studies in Middle English Linguistics. Mouton de Gruyter \& Co. Berlin.

International journal of computer science issues. www.ijcsi.org

Jespersen, Otto. 2006. Essentials of English Grammar. Taylor \& Francis Group. UK.

Journal of Computer Science \& Technology . http://journal.info.unlp.edu.ar/journal

Mair. Christian. 2006. Twentieth-century English: History, Variation and Standardization. Cambridge University press. Cambridge.

Quirk R., S. Greenbaum G. Leech, and J. Svartvik 1985. A Comprehensive Grammar of the English Language. London. Longman..

Rosenbaum, Peter. 1967. The grammar of English predicate complement constructions. Cambridge MA: The MIT Press.

Stageberg, N.C. 1981. An Introductory English Grammar, $2^{\text {nd }}$ ed. New York: Holt, Rinehart and Winston Ltd.

Wierzbicka, A. 1988. The semantics of Grammar. Amsterdam/Philadelphia: John Benjamins. 